\title{
EXPERIMENTAL RESEARCH ON PORE PRESSURE ATTENUATION IN RUBBLE-MOUND BREAKWATERS
}

\author{
Dieter Vanneste and Peter Troch ${ }^{1}$
}

\begin{abstract}
The paper describes the pore pressure measurements in a small scale breakwater model performed at Ghent University, Belgium. Two phenomena related to the pore pressure distribution within the breakwater are discussed: the amount of energy dissipation through the armour and filter layer (represented by the 'reference pressure') and the exponential pore pressure attenuation inside the core of the breakwater. The test results are compared with results from literature and with the empirical damping model presented by Burcharth et al. (1999) and Troch (2000). Magnitudes of the reference pressures are found to be strongly dependent on the wave steepness. The pore pressure attenuation obtained from the present experiments shows to be in accordance with the empirical damping model. A suggestion is made for a better prediction of the damping coefficient by eliminating the influence of the wave height in the empirical damping model.
\end{abstract}

Keywords: rubble-mound breakwater; wave attenuation, pore pressures, physical modelling

\section{INTRODUCTION}

Permeable coastal structures such as rubble mound breakwaters are of great interest in coastal and harbour engineering. These structures are capable of protecting a coastal area from excessive wave action by dissipating the incident wave energy through friction inside the porous body of the structure. When studying the structural response of rubble mound breakwaters to wave loading, the knowledge of pore pressures and related wave attenuation inside the porous structure is important since the pore pressures affect most responses, such as wave run-up, wave overtopping, reflection, transmission and the hydraulic and geotechnical stability of the breakwater.

Although designing and constructing a stable rubble mound structure continues to rely heavily on past experience and physical modelling, the development and use of numerical models to analyze the structural response of the breakwater to wave loading is growing rapidly nowadays. To validate the performance of a numerical wave flume with regard to the interaction of the porous structure with waves, reliable pore pressure data are needed, either from prototype measurements or from physical model tests. In this research, the pore pressure distribution has been determined within the core of a physical model, built at scale 1:30 in the wave flume of Ghent University.

Two phenomena related to the pore pressure distribution in the breakwater core are discussed and compared with experimental results reported by various authors: the reference pressures at the interface between core and filter layer and the rate of pore pressure attenuation within the core.

\section{BACKGROUND}

In most of the numerical models which are used to study flow in permeable media, the frictional forces exerted by a porous medium are commonly described by the Forchheimer equation, which in the case of a one-dimensional steady flow takes the form:

$$
I=\alpha \frac{(1-n)^{2}}{n^{3}} \frac{v}{g d_{50}^{2}} u+\beta \frac{1-n}{n^{3}} \frac{1}{g d_{50}} u|u|
$$

where $I$ is the pressure gradient, $u$ is the discharge velocity, $n$ is the porosity, $d_{50}$ is the mean grain diameter and $v$ the kinematic fluid viscosity. The coefficients $\alpha$ and $\beta$, often referred to as shape parameters, depend on the Reynolds number $\left(\mathrm{Re}=\mathrm{U} \cdot \mathrm{d}_{50} / v\right)$, grain shape and grading of the stone material.

On the right-hand side of eq. (1), the first term refers to the laminar and the second term to the turbulent contribution. The shape coefficients $\alpha$ and $\beta$ need to be determined experimentally for different types of stone material and different regimes of flow (laminar or turbulent), see eg. Van Gent (1995) and Burcharth and Andersen (1995).

According to Biesel (1950), the amplitude of pressure oscillation in a porous body exposed to harmonic waves will decrease exponentially in the direction of wave propagation (see Fig. 1), taking the following expression:

$$
p(x)=p_{0} e^{-\delta \frac{2 \pi}{L^{\prime}} x}
$$

\footnotetext{
${ }^{1}$ Dept. of Civil Engineering, Ghent University , Technologiepark 904, 9052 Zwijnaarde, Belgium dieter.vanneste@ugent.be, peter.troch@ugent.be
} 
where $x$ is the horizontal coordinate ( $x=0$ corresponds to the interface between core and filter layer), $p(x)$ is the pore pressure height (ie. the double amplitude of the pressure oscillation) at location $x, p_{0}$ is the reference pressure at the interface between core and filter layer, $\delta$ is the damping coefficient, $L^{\prime}$ is the wave length in the core $\left(\mathrm{L}^{\prime}=\mathrm{L} / \sqrt{D}\right) . L$ is the length of incident wave and $D$ is a coefficient to account for seepage length as a result of the deviation of the flow path caused by the grains. Le Mehaute (1957) reports the empirical value of $D=1.4$ for quarry rock material. Miche (1960) obtained a theoretical value for $D$ equal to 1.5 .

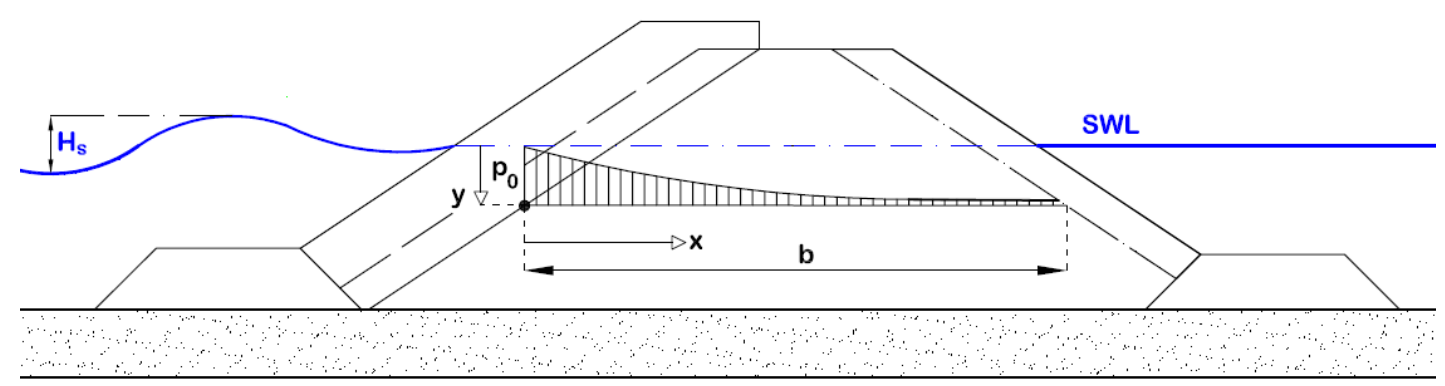

Figure 1. Definition sketch of attenuation of pore pressure height within the core of a rubble mound breakwater

The damping coefficient $\delta$ accounts for the rate of energy dissipation along the direction of wave propagation and can be determined for a given distance y below SWL by fitting of expression (2) to the pressure recordings at several locations below SWL. An empirical expression for the damping coefficient is given by Burcharth et al. (1999) and Troch et al. (2002):

$$
\delta=a_{\delta} \frac{\sqrt{n} L_{p}^{2}}{H_{S} b}
$$

where $n$ is the porosity of the core, $b$ is the width of the core at a given depth (Figure 1) and $H_{s}$ and $L_{p}$ are the wave height and length, respectively. The coefficient $a_{\delta}$ is determined by a linear regression analysis using the $\delta$ values determined from the pressure recordings. Troch et al. (2002) reported a value of $a_{\delta}=0.014$ based on pore pressure measurements in a large scale model (GWK) and prototype measurements at Zeebrugge (Belgium).

\section{EXPERIMENTAL TEST SETUP}

\section{Model geometry}

The experimental research was conducted in the wave flume of Ghent University, Dept. of Civil Engineering, which is $30 \mathrm{~m}$ long, $1.2 \mathrm{~m}$ high and $1 \mathrm{~m}$ wide. The breakwater model is based on the design of a low-crested breakwater, scaled at 1:30 and slightly modified within the scope of the present experiments.

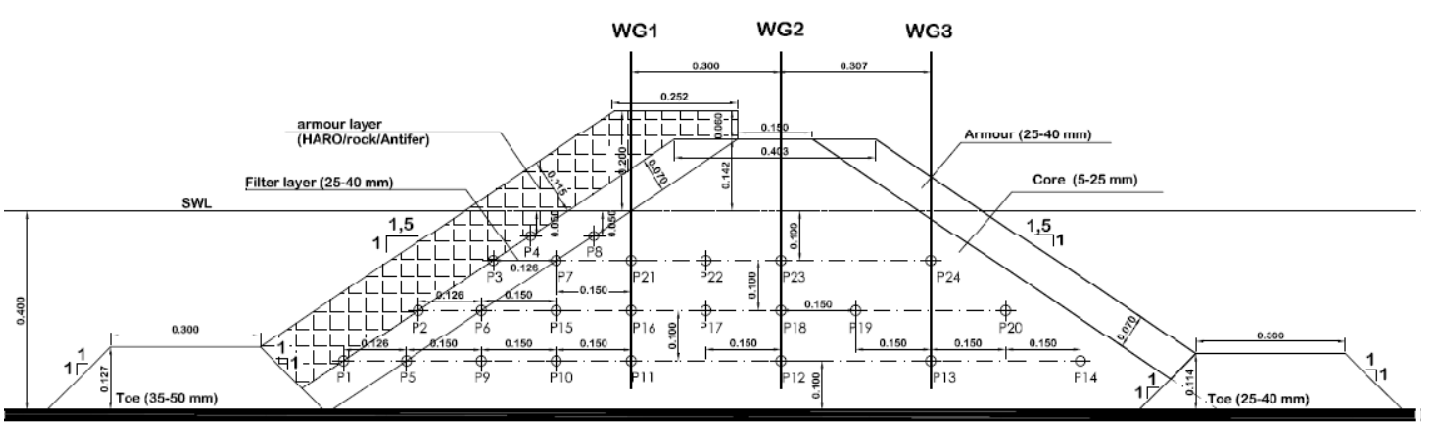

Figure 2. Cross section of the breakwater model (dimension are in $\mathbf{m}$ )

The design is a conventional layered breakwater model, consisting of a core, filter layer and armour layer, as shown in Figure 2. The crest level of $0.2 \mathrm{~m}$ above the still water level (SWL) was chosen in accordance with the no-overtopping condition and the hydraulic boundary conditions (see further). 
In order to investigate the relative contribution of the armour and filter layer to the total wave dissipation, tests were performed under different model configurations; consisting of the core alone, the core and filter layer and the full breakwater model. In the full breakwater model, three different types of armour layers were used : HARO units $(0.542 \mathrm{~kg})$, Antifer units $(0.330 \mathrm{~kg})$ and rock material $(35 / 50$ $\mathrm{mm}, 0.098-0.196 \mathrm{~kg})$. The different model configurations and their corresponding nomenclature are summarized in Table 1.

Table 1. Model configurations

\begin{tabular}{|cl|}
\hline stage & description \\
\hline 1 & core alone \\
2 & core + filter layer \\
3 & core + filter + armour layer(HARO units) \\
4 & core + filter + armour layer (rock $35 / 50 \mathrm{~mm}$ ) \\
5 & core + filter + armour layer (Antifer units) \\
\hline
\end{tabular}

\section{Selection of core material}

The scale model tests have been designed to compare the pore pressure distribution and wavestructure interaction with numerical simulations of the same test setup. To model the porous flow in the core, the Forchheimer equation (1) is used, thus the knowledge of the shape parameters $\alpha$ and $\beta$ is required, which on their turn depend on the flow regime, grain shape and grading. To select the stone material for building the breakwater model core, different types of stone material and corresponding shape parameters were reviewed, which have been experimentally determined in permeameter flow tests by various researchers. Taking into consideration the target stone dimensions determined by the model scale 1:30, stone sample 'test $2^{\prime}(5-25 \mathrm{~mm})$ in the report of Burcharth and Christensen (1991) was selected as the core material. Using the available sieves in the laboratory, this stone fraction was reconstructed as good as possible.

The shape class of a representative sample taken from the stone material was determined according to the method specified by CIRIA-CUR. The parameters $l$ and $d$ represent the maximum axial length and maximum axial width, respectively. The resulting stone size gradation and stone shape distribution are represented in Figure 3 and Figure 4.

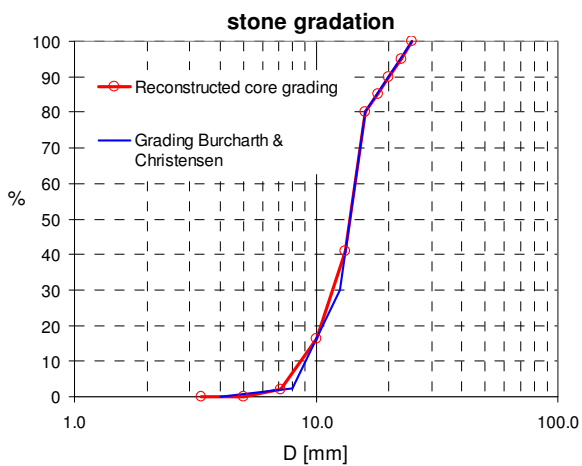

Figure 3. Stone gradation of original and reconstructed core material

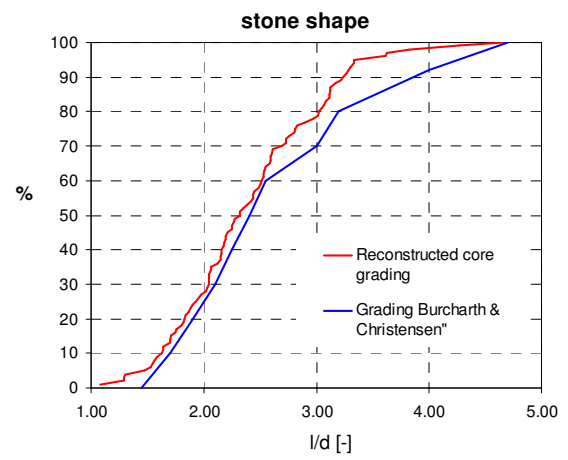

Figure 4. Stone shape distribution of original and reconstructed core material

An important factor appearing in the Forchheimer equation is the porosity $n$, since it is raised to the third power in eq. (1). Porosity measurements on the core material were carried out both in a recipient and 'in situ', ie. a porosity measurement of the material as built in the wave flume. Measurements 'in situ' are preferred because of the uncertainties involving the compactation of the stones when subjected to the wave impact, in comparison with a sample compacted in a recipient. A procedure was developed to measure the porosity 'in situ', by weighing the stones in saturated surface dry conditions, measuring the water mass added to a control volume and measuring the bulk volume occupied by the stones with a laser apparatus commonly used to track the erosion evolution of stone surfaces. Moreover, this measurement technique allows to measure the degree of compactation of the core material under wave loading.

A last parameter needed in the determination of the porosity is the stone density, measured from a representative sample in saturated surface dry conditions. The characteristics of the original and the reconstructed core material are summarized in Table 2. 
Table 2 : Target and reconstructed stone properties of the model core

\begin{tabular}{|lcccccc|}
\hline & size & grading & avg. shape & shape class & porosity & density \\
& $d_{50}$ & $d_{85} / d_{15}$ & $l / d$ & & $n$ & $\rho_{\text {ssd }}\left[\mathrm{kg} / \mathrm{m}^{3}\right]$ \\
& {$[\mathrm{mm}]$} & {$[-]$} & {$[-]$} & & {$[-]$} & \\
$\begin{array}{l}\text { sample test 2 B\&C } \\
\begin{array}{l}\text { reconstructed core } \\
\text { material }\end{array}\end{array} 13.8$ & 1.80 & 2.40 & irregular & 0.455 & 2680 \\
\hline
\end{tabular}

\section{Hydraulic boundary conditions}

A constant water depth of $0.4 \mathrm{~m}$ was used. The tested program consisted of regular and irregular wave trains. The range of wave heights for the regular waves were between 0.02 and $0.10 \mathrm{~m}$, and the range of wave periods varied between 1.09 and $2.6 \mathrm{~s}$. Irregular wave were generated according to a JONSWAP-spectrum $(\gamma=3.3)$, with significant wave heights from 0.06 to $0.10 \mathrm{~m}$ and peak periods from 1.3 to $2.6 \mathrm{~s}$.

Both regular and irregular wave trains consisted of 500 waves. This provided a sufficient duration to eliminate transient effects in the pressure recordings and to track the potential water level set-up in the breakwater core.

The crest level and wave heights were chosen accordingly to avoid heavy overtopping which on its turn would influence the pore pressure measurements in the region close to SWL. In a few combinations of specific wave height and period, light to moderate wave overtopping was observed. In these cases, the crest level was raised with a removable crown element to avoid overtopping.

\section{Instrumentation}

For the measurement of the internal pore pressures induced by wave action, 24 pressure sensors were installed inside the core of the breakwater and at the interface between armour and filter layer. The positions of the pressure sensors are indicated in Figure 2. The sensors are placed in 3 levels, separated $0.1 \mathrm{~m}$ from each other, the lowest level at a distance of $0.1 \mathrm{~m}$ above the bottom.

The pressure transducers measure absolute pressures which enables a high-precision measurement. A sufficient number of sensors were installed in order to monitor the pore pressures with a high spatial resolution.

The water movement inside the breakwater core was measured with three wave gauges (WG1/2/3, see Figure 2), protected by a perforated plastic pipe. The pictures included hereafter (Figure 5-Figure 8) show the measurement instrumentation and the test facility.

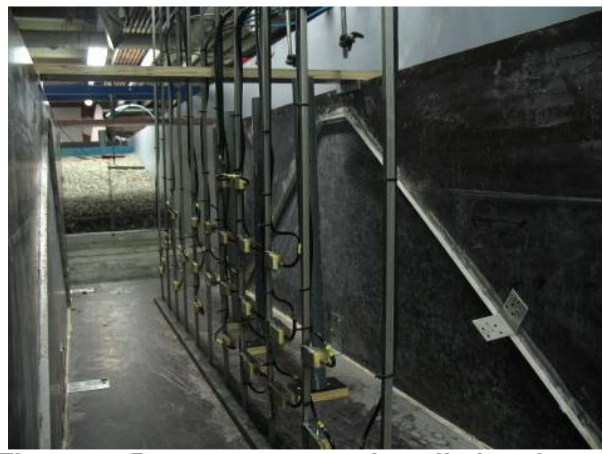

Figure 5 : Pressure sensors installed on frame

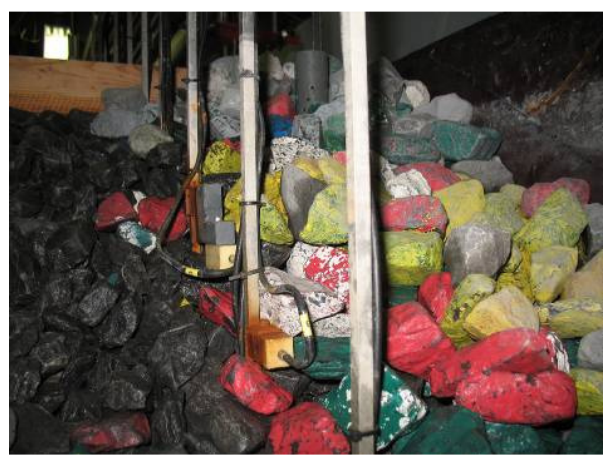

Figure 7: Detail of pressure sensors between core and filter layer

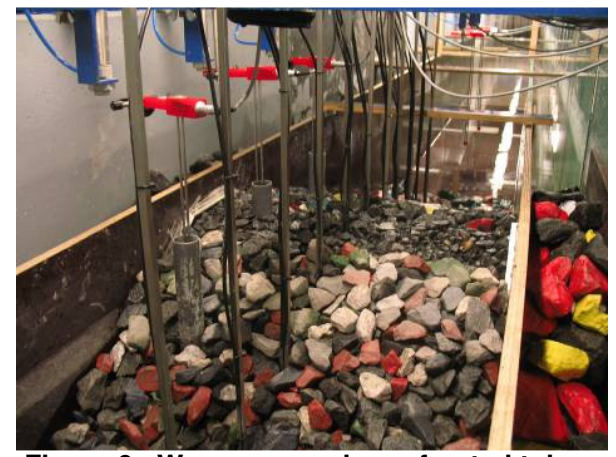

Figure 6 : Wave gauges in perforated tubes

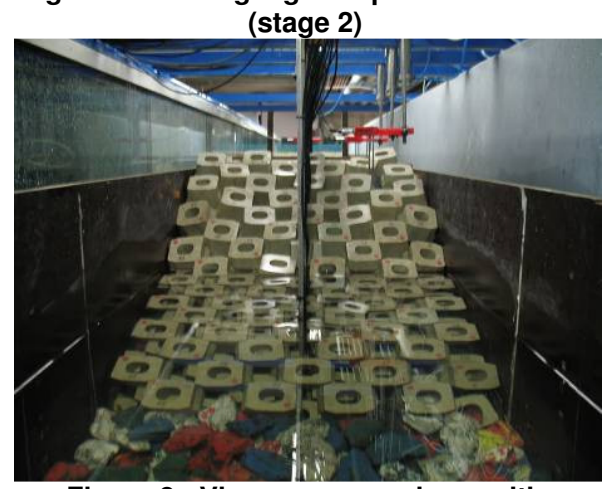

Figure 8 : View on armour layer with HARO units (stage 3) 


\section{RESULTS}

\section{Reference pressures at interface core-filter layer}

In the following, the term 'pressure' or 'pore pressure' refers to the excess pore water pressure which is solely induced by wave action. The term '(pore) pressure height' is used in the same way as for water waves to designate the height of the pressure fluctuations. The total pore water pressure is the hydrostatic pressure added with the pressure height. The recorded pressure time series are processed in a similar way as with surface elevations. In experiments with regular waves, the pressure variation is characterized by the mean pressure height $p_{m}$, whereas for irregular waves a significant pressure height $p_{s}$ is obtained.

The pressure drop through the armour and filter layer is represented by the dimensionless reference pressure, ie. the ratio between the dynamic pressure height oscillation $p_{\delta} \rho g$ and the incident wave height $H$. The reference pressures are measured by the 4 sensors P5 to P8, which are located on the interface between core and filter layer (Figure 9).

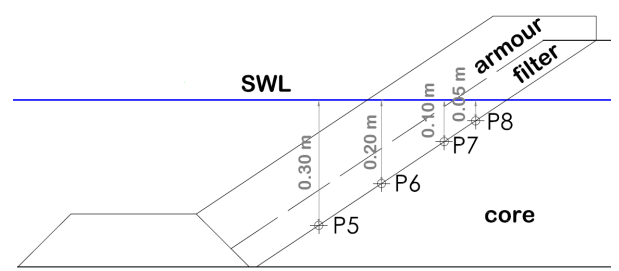

Figure 9. Location of pressure sensors P5-P8

The results from the present experimental tests are compared with results from large scale testing in GWK and prototype measurements on the Zeebrugge breakwater (Belgium), according to Troch (2000). The results from both data sets indicate that the reference pressures show a weak dependence on the wave steepness and distance (y) of the pressure sensor under SWL, see Figure 10 and Figure 11. For practical use, a constant value for the reference pressure equal to 0.55 was proposed by Burcharth et al. (1999), assuming a constant value along the interface between filter layer and core. Close to the SWL $\left(y / H_{s}<1\right)$, the pressures are affected by turbulence and the proposed practical value is not valid.

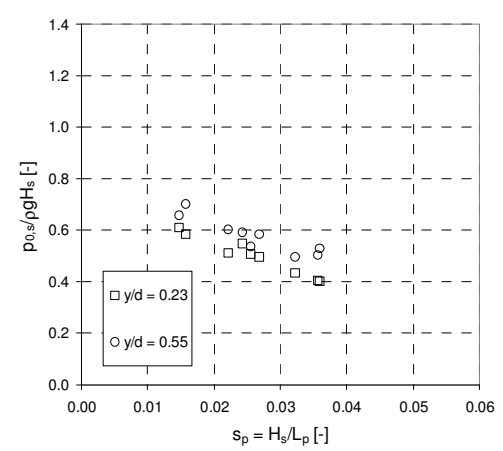

Figure 10. GWK data

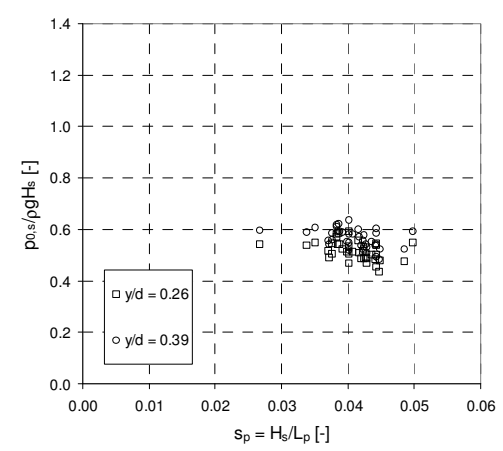

Figure 11. Zeebrugge data

The present tests however show a stronger correlation between the reference pressures and the wave steepness. An example of tests with HARO armour units is shown in Figure 12 (monochromatic waves) and Figure 13 (irregular waves). From these figures it is observed that the amount of energy dissipation through the armour and filter layer increases with increasing wave steepness. This may be explained as the degree of dissipation results to be strongly dependent on the magnitude of the surf similarity parameter $\xi$ (or wave steepness for a fixed slope), representing the shape of the breakers on the outer slope. A similar observation was reported by Oumeraci and Partenscky (1990), who determined the dissipation of wave motion through the armour and filter layer of a large scale breakwater model by measuring the wave run-up on the armour, filter and core slope. As a result from these measurements, the amount of energy dissipation showed to be dependent on the surf similarity parameter $\xi$. Smaller values of $\xi$ (typically smaller than 2 to 3 ) correspond to spilling and plunging breakers which are associated with a high degree of air entrainment and high impact velocities, resulting in a high degree of dissipation. Collapsing and surging breakers $(\xi>4)$ yield lower dissipation. 


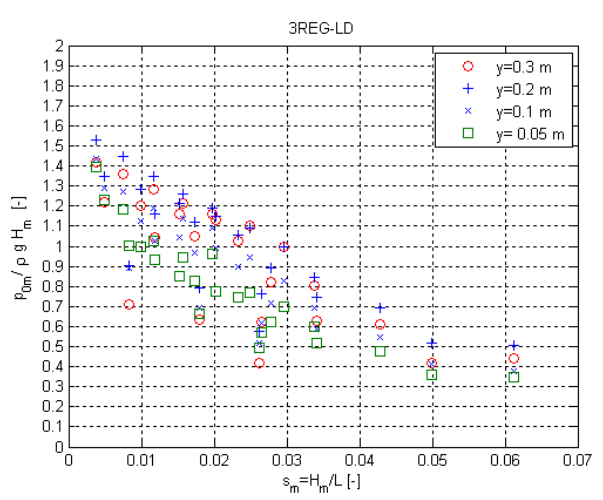

Figure 12. $p_{0, m} / \rho g H_{m}$ vs. wave steepness, for regular waves, stage 3

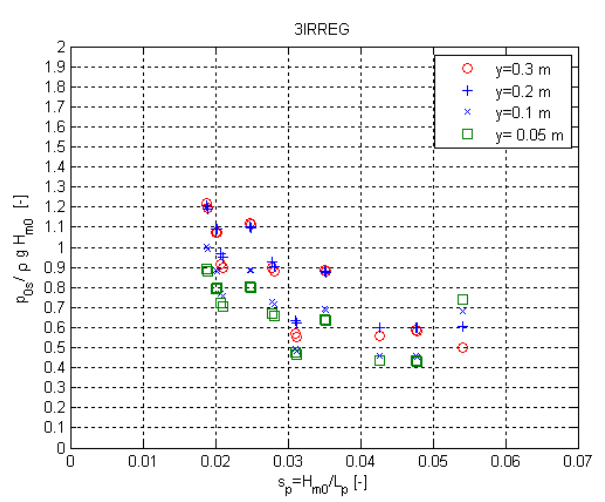

Figure 13. $p_{0, s} / \rho g H_{m o}$ vs. wave steepness, for irregular waves, stage 3

From Figure 12 and Figure 13 it is observed that the reference pressure exceeds the value of 0.55 proposed by Burcharth, especially in the case of small values of wave steepness $(s<0.03)$. A reference pressure larger than unity suggests that the reference pressure is highly influenced by wave run-up processes on the armour slope. First results from comparative numerical simulations, currently being carried out, confirm this hypothesis and suggests that scale effects play a significant role. The dissimilarity regarding air entrainment (turbulent flow dissipation) and the amplitude of viscous forces affects the energy dissipation through the armour and filter layer, leading to a significant difference in reference pressure for the different scale models.

When analyzing the individual influence of the two wave parameters defining the wave steepness, i.e. (wave height $H_{m}$ or $H_{m 0}$ ) and wave period $\left(T_{m}\right.$ or $T_{p}$ ), it is seen that both parameters contribute to the observed decrease of reference pressure when the wave steepness is increased. From the different graphs showing the relation between reference pressure and wave period (Figure 14, Figure 15) and wave height (Figure 16, Figure 17), a clear increase of the reference pressure with increasing wave period is noticed. On the other hand, the relation between the reference pressure and the wave height is not so clear. A slight tendency of decreasing reference pressures with increasing wave height is observed (more clearly for regular tests than for irregular tests), but generally for a given value of the wave height, the values show a large spreading. This leads to the conclusion that of the two parameters that determine the wave steepness, the wave period has a dominating influence on the reference pressure. The latter can also be demonstrated if a comparison is made of the results of individual tests corresponding to an equal (or a very similar) value of wave steepness but a different value of wave period. In this case a clear distinction in the values of reference pressures is observed, with the lowest reference pressures corresponding to the smallest wave period.

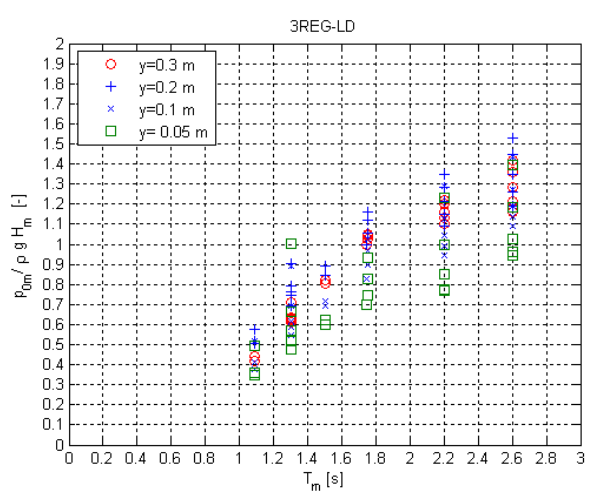

Figure 14. $p_{0, m} / \rho g H_{m}$ vs. wave period for regular waves, stage 3

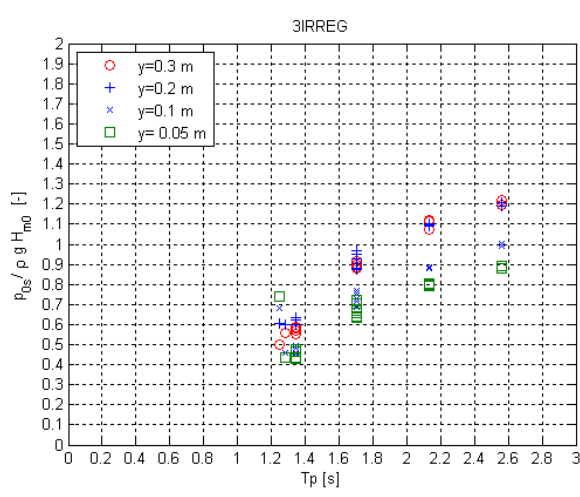

Figure 15. $\mathrm{p}_{0, \mathrm{~s}} / \mathrm{\rho g} \mathrm{H}_{\mathrm{mo}}$ vs. wave period for irregular waves, stage 3 


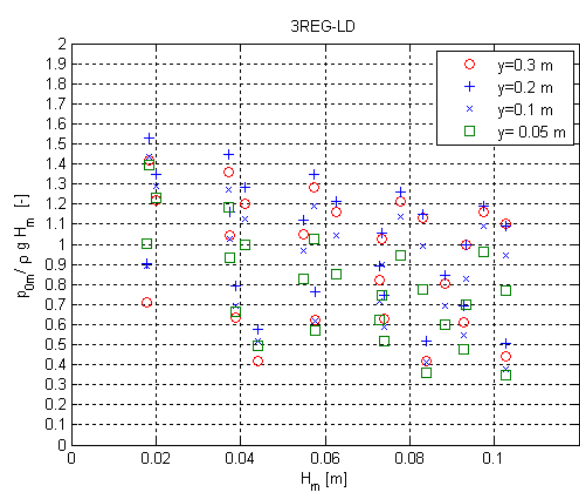

Figure 16. $p_{0, m} / \rho g H_{m}$ vs. wave height for regular waves, stage 3

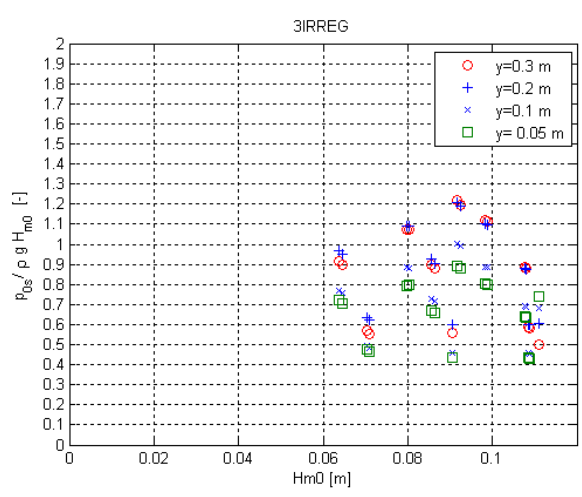

Figure 17. $p_{0, s} / \rho g H_{m o}$ vs. wave height for irregular waves, stage 3

The three armour types do not show any clear differences regarding the energy dissipation through the armour layer, as can bee seen in Figure 18 and Figure 19, where the reference pressure measured by sensor P5 (near the bottom) is shown for the 3 different types of armour layers.

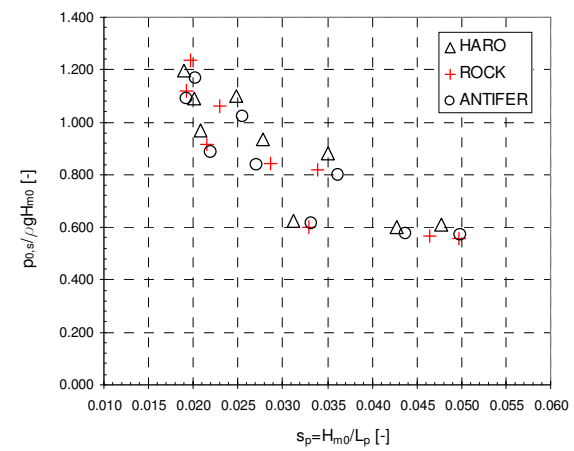

Figure 18. $p_{0, s} / \rho g H_{m o}$ vs. wave steepness, for different armour types

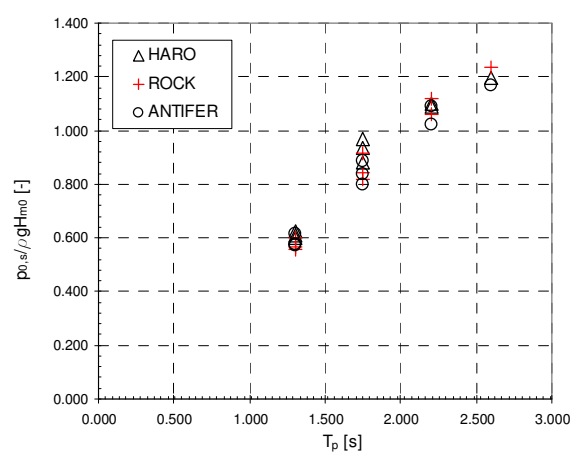

Figure 19. $p_{0, s} / \rho g H_{m 0}$ vs. wave period, for different armour types

\section{Rate of pore pressure attenuation within the core}

The damping coefficient $\delta$ is calculated by fitting expression (2) through the measured pore pressures using a least square method. In this way, for each level $y$, a value for the damping coefficient is obtained. Figure 20 shows an example of the exponential fitting procedure, for irregular waves, stage 3 (HARO armour units).

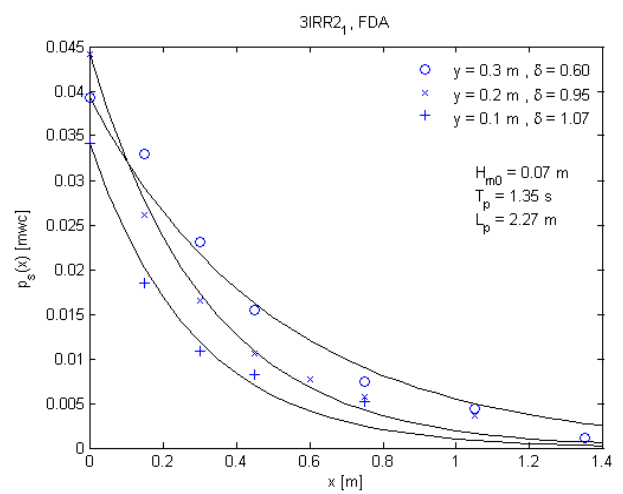

Figure 20. Example of exponential fitting through measured pore pressure values

Figure 20 shows that the damping coefficient $\delta$ decreases for increased depth $y$, when the same wave conditions apply. This can be explained by the friction losses which become smaller as the degree of turbulence decreases when the distance from SWL increases. Moreover, the analyzed results show that the damping coefficient increases for increased wave period, when the same depth and wave height apply, see Figure 21 (left). Both conclusions are confirmed by Oumeraci and Partenscky (1990), Troch et al. (2002) and Helgason (2004). 

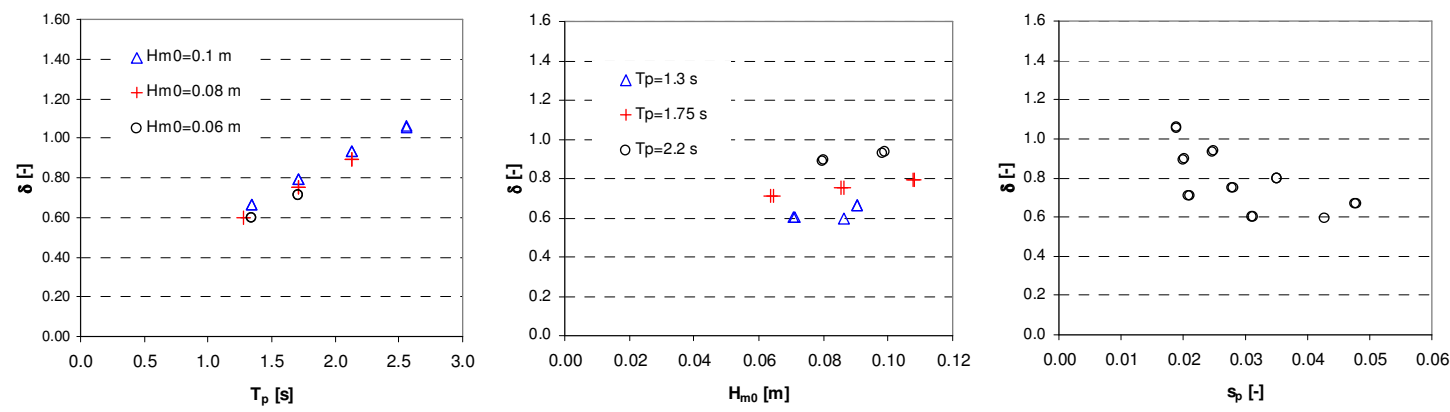

Figure 21. $\delta$ vs. $T_{p}, H_{m 0}$ and $s_{p}$, for irregular waves, stage $3(y=0.3 \mathrm{~m})$

The relation between $\delta$ and the incident wave height on the other hand is not so clear. The previously cited authors report that $\delta$ decreases for increased wave height (for equal depth and wave period), whereas in the present tests $\delta$ shows a weak tendency to increase with increasing wave height. However, the damping coefficient is correlated more strongly with the wave period, than with wave height, as can be seen by comparing Figure 21 left and middle. When $\delta$ is plotted as a function of wave steepness (Figure 21, right), it appears that $\delta$ decreases for increasing wave steepness, ie. steeper waves penetrate deeper in the breakwater core.

The previous conclusions agree with the empirical formula (3) for the damping coefficient, rewritten as follows:

$$
\delta=a_{\delta} \frac{\sqrt{n} L_{p}^{2}}{H_{s} b}=a_{\delta} \frac{\sqrt{n} L_{p}}{s_{p} b}
$$

where $n$ is the porosity of the core material, $L_{p}$ the wave length, $s_{p}$ the wave steepness and the position under SWL, characterized by the width $b$ of the core at a depth $y$ (see Figure 1). Figure 22 shows the result of a linear regression analysis applied to the $\delta$ values of all tests with irregular waves, which yields a value for $a_{\delta}$ equal to 0.0123 in expression (4).

This value agrees reasonably well with the value of $a_{\delta}$ equal to 0.010 , based on an extensive analysis of data from the large scale GWK model and Zeebrugge prototype measurements (Figure 23). In the present regression analysis, the pore pressure measurements which do not fulfill the condition $y / H_{m 0}>0.85$ were omitted. A practical value of 0.85 was assigned to the parameter $y / H_{m 0}$ in this criterion, indicating the relative position of the pressure sensor with respect to the SWL. In this way, the pressure sensors that are located in the region close to the SWL where strong turbulence exists are excluded from the analysis, since the exponential model (2) is not capable of describing the pore pressure attenuation accurately in this region. It is mentioned that no such criterion was applied in a previous analysis of the same data, performed by Troch (2002), which yielded a value of $a_{\delta}$ equal to 0.014 .

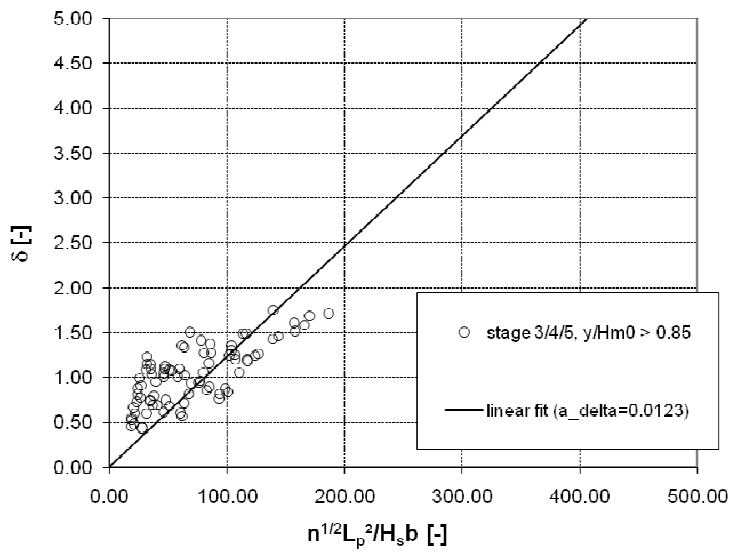

Figure 22. Fitting of $a_{\delta}$ according to eq. (4), for the present tests

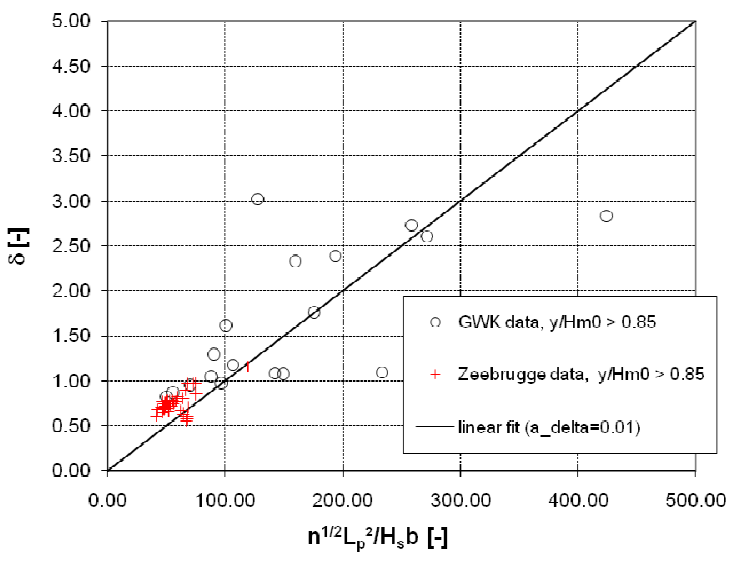

Figure 23. Fitting of $a_{\delta}$ according to eq. (4), GWK and Zeebrugge data 
The values of the damping coefficient from the GWK dataset show a considerable scatter for large values $(>100)$ of the dimensionless predictor. The quality of the regression analysis is generally rather poor, as can be seen from the values of the coefficient of determination given in Table 3. The coefficient of determination is defined as unity minus the proportion of the regression sum of squares to the total sum of squares.

Table 3 : Coefficient of determination for different types of regression analysis of damping coefficient $\delta$

\begin{tabular}{|ccc|}
\hline type of linear fit & present tests & $\begin{array}{c}\text { large scale \& Zeebrugge } \\
\text { prototype data }\end{array}$ \\
$\delta \sim \mathrm{n}^{1 / 2} \mathrm{~L}_{\mathrm{p}} / \mathrm{H}_{\mathrm{s}} \mathrm{b}$ (eq.4) & 0.35 & 0.52 \\
$\delta \sim \mathrm{n}^{1 / 2} \mathrm{~L}_{\mathrm{p}} / \mathrm{b}$ (eq. 5) & 0.78 & 0.65 \\
\hline
\end{tabular}

It is assumed that the main source for the scatter in the regression analysis according to eq. (4) is caused by the presence of the wave height in the dimensionless predictor value, as can be seen in Figure 21 (middle). Removing the wave height from the dimensionless predictor value improves the correlation. In order to maintain a dimensionless predictor value, the wave steepness is eliminated from eq. (4), resulting in the following regression analysis:

$$
\delta=a_{\delta} \frac{\sqrt{n} L_{p}}{b}
$$

The regression analysis according to eq. (5) is shown in Figure 24 and Figure 25, for the results from the present tests and the results from large scale GWK and Zeebrugge prototype data, respectively. In Table 3, the values of the determination coefficient are given, showing an increased determination by the prediction according to eq. (5) when compared to the analysis according to eq. (4). Accordingly, it is suggested to use eq. (5) for a prediction of the damping coefficient $\delta$, with a value of $a_{\delta}$ approx. equal to 0.5 . The value of the regression coefficient will be confirmed by further analysis using the results of numerical modeling of the experimental tests, both small and large scale, in a RANS VOF model.

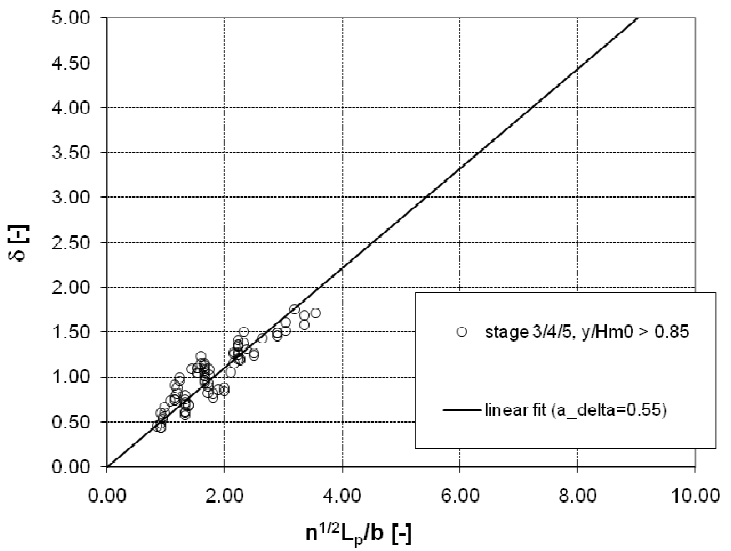

Figure 24. Fitting of $a_{\delta}$ according to eq. (5), for the present tests

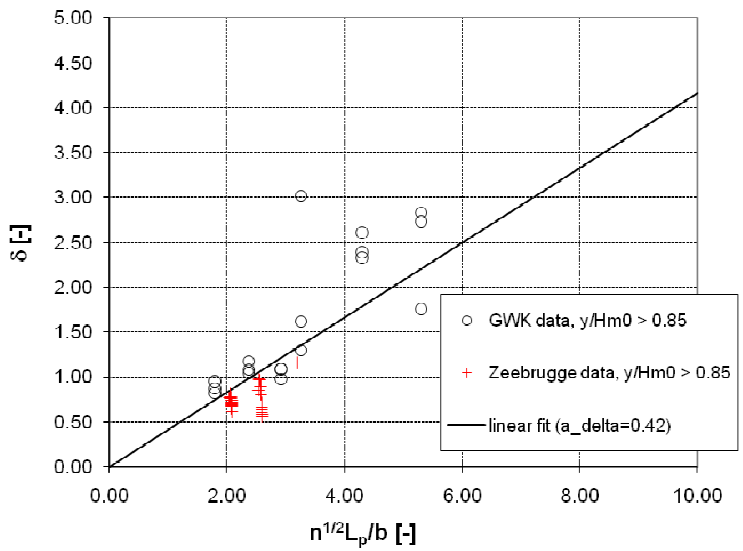

Figure 25. Fitting of $a_{\delta}$ according to eq. (5), GWK and Zeebrugge data

\section{CONCLUSIONS}

Pore pressure measurements were performed on a small scale (1:30) model of a conventional layered breakwater, consisting of a core, filter and armour layer. Three different types of armour layers were tested.

The reference pressures, accounting for the amount of energy dissipation through armour and filter layer, show a clear dependence on the wave steepness, more specifically on the wave period. For lower values of wave steepness, a significantly higher reference pressure in the small scale model is observed compared to results from large scale model tests or prototype measurements. Scale effects are assumed to cause this difference in reference pressure in the case of low values of wave steepness (collapsing or 
surging breakers). No significant differences in reference pressures were observed for the three different types of armour layers.

The empirical formula for the damping coefficient $\delta$ (Burcharth et al. 1999, Troch et al. 2002) was validated with the present tests. To establish the empirical formula for the damping coefficient, the pore pressure measurements in the region close to SWL, affected by strong turbulence, were not taken into consideration when applying the regression analysis.

A suggestion for an improved prediction of the damping coefficient is given by eliminating the wave height in the dimensionless predictor. This method was applied to the experimental values of $\delta$ from both the present tests and from large scale and prototype experiments.

\section{ACKNOWLEDGEMENTS}

Marc Willems (Flanders Hydraulics Research) is greatly acknowledged for providing the Antifer armour model units used in this research.

\section{REFERENCES}

Biesel, F. 1950. "Equations de l'écoulement non lent en milieu permeable. » La Houille Blanche Nr.2, Mars-Avril 1950.

Burcharth, H.F., Christensen, C. 1991. "On stationary and non-stationary porous flow in coarse granular materials." MAST G6-S report, Dept. of Civil Engineering, Aalborg University, Denmark.

Burcharth, H.F., Andersen, O.H. 1995. "On the one-dimensional steady and unsteady porous flow equations." Coastal Engineering, Vol. 24, 233-257, Elsevier.

Burcharth, H.F., Liu, Z., Troch, P., 1999. "Scaling of core material in rubble mound breakwater model tests." Proceedings of the 5th International Conference on Coastal and Port Engineering in Developing Countries (COPEDEC), Cape Town (South Africa), 1518-1528.

Bürger, W. , Oumeraci, H. , Partenscky, H.W. 1988. "Geohydraulic invesigations of rubble mound breakwaters", Proc. 21th International Conference on Coastal Engineering, ASCE, 2242-2256.

CIRIA/CUR 1991 "Manual on the use of rock in coastal and shoreline engineering", CIRIA Publication 83, CUR Report 154.

Helgason, E., Burcharth, H.F., Grüne, J. 2004."Pore pressure measurements inside rubble mound breakwaters", Proceedings of 29th International Conference on Coastal Engineering, ASCE, 37013713.

Le Mehauté, B. 1957. "Permeabilité des digues en enrochments aux ondes de gravité périodiques. La Houille Blance nr.6, 903-919.

Miche, R. 1960. "Recherches théoriques sur les écoulements de filtration non permanents", 5e Journées de l'Hydraulice,

Oumeraci, H., Partenscky, H.W. 1990. "Wave-induced pore pressures in rubble mound breakwaters." Proceedings of 22th International Conference on Coastal Engineering, ASCE, 1334-1347.

Troch, P. 2000. "Experimental study and numerical simulation of wave interaction with rubble mound breakwaters.", PhD Thesis, Dept. of Civil Engineering, Ghent University, Belgium., 5-25.

Troch, P., De Rouck, J., Burcharth, H.F. 2002. "Experimental study and numerical modeling of wave induced pore pressure attenuation inside a rubble mound breakwater", Proc. 28th International Conference on Coastal Engineering, ASCE, 1607-1619

van Gent, M.R.A. 1995. "Wave interaction with permeable coastal structures", PhD Thesis, TU Delft, The Netherlands. 